\title{
Total kalça artroplastisinde endikasyonlar ve hasta seçimi
}

\author{
Indications for total hip arthroplasty and patient selection
}

\author{
İbrahim Azboy, Abdullah Demirtaş, Bekir Yavuz Uçar
}

Dicle Üniversitesi Tıp Fakültesi Ortopedi ve Travmatoloji Anabilim Dalı, Diyarbakır

Dejeneratif ve inflamatuar hastalıklar başta olmak üzere birçok kalça sorunu, hastada ağrıya ve kalça hareketlerinde kısıtlanmaya neden olmaktadır. Ağrısız ve hareketli bir kalça eklemine yeniden kavuşmak hastaların temel isteğidir. Total kalça protezi (TKP) ameliyatı, ortopedik cerrahinin en başarılı ameliyatları arasındadır. Biyomühendislikteki gelişmelerle birlikte giderek daha dayanıklı ve uzun ömürlü olması beklenen implantlar üretilmektedir. Ayrıca hastalar eskiye oranla, ağrılarını ve kısıtlanan aktivitelerini olduğu gibi kabul etmek yerine, ağrılarının tamamen giderilmesini ve normal vücut fonksiyonlarının devam etmesini istemektedirler. Bu nedenle, uygulanan TKP sayısında artış olduğu görülmektedir. Tedavide, başlangıçta konservatif tedavi yöntemleri uygulanmalıdır. Hastaya aktivitelerini düzenlemesi, kilo vermesi, analjezik alması ve baston kullanması önerilmelidir. Konservatif tedaviler başarısız kaldığında TKP önerilmelidir. TKP'nin temel endikasyonu kalçada, radyolojik incelemeyle de gözlendiği gibi, yıkımın eşlik ettiği ağrıdır. Hastanın kalça ekleminde veya vücudun herhangi bir yerinde aktif enfeksiyon bulunması TKP için kesin kontrendikasyon olarak kabul edilmektedir. Charcot artropatisi, abduktor kasların yetersizliği veya kaybı, demans ve başarılı kalça artrodezi ise göreceli kontrendikasyon olarak belirtilmektedir. TKP majör bir cerrahidir ve son seçenektir. Bu nedenle TKP'de endikasyon ve hasta seçiminde titiz davranmak başarıyı arttıracaktır.

Anahtar sözcükler: osteoartrit, kalça; total kalça replasmanı; kontrendikasyonlar; hasta seçimi
Many hip problems, particularly degenerative and inflamatuary hip diseases, result in hip pain and restriction of motion. The main demand of patients is to relieve pain and regain hip motion. Total hip arthroplasty (THA) is among the most successful orthopaedic surgeries. In parallel with the improvements in bioengineering, the implant materials have been manufactured which are expected to be more durable and longstanding. Besides nowadays, instead of accepting the pain and restricted activity as it is, patients demand to get rid of their pain completely and continue their normal bodily function. Therefore, currently there is an increase in number of THA applications. In the early treatment of the hip diseases, conservative measures should be used in principle. Giving weight, utilizing a cane, taking analgesics, modifying and restricting some activities should be the initial proposals to the patient. THA should be recommended if these conservative measures fail. The primary indication of THA is the pain in the presence of a destructive process in the hip joint as evidenced on radiographs. Active infection in the hip joint or elsewhere in the body are accepted as decisive contraindication. Charcot arthropathy, an absence or insufficiency of abductor musculature, demantia and successful hip arthrodesis are accepted as relative contraindications. THA is a major surgery and should always be the last option for treatment. Therefore, being meticulous during the indication and selection of the patient will increase the success of THA.

Key words: osteoarthritis, hip; total hip replacement; contraindications; patient selection
T otal kalça protezi (TKP) ameliyatı, yüksek başarı oranı ile uygulanan ortopedi ameliyatlarının başında gelmektedir. ${ }^{[1,2]}$ TKP ameliyatı ağrılı ve hareketleri kısıtlı kalça eklemi nedeniyle yıllardır sorun yaşayan hastaları, yeniden hareketli ve ağrısız günlerine kavuşturma olanağı sağlayan, deyim yerindeyse mucizevi bir tedavi yöntemidir. ${ }^{[1,2]}$ TKP'de cerrahi teknik standart hale gelmiş ve komplikasyon oranları kabul edilebilir seviyeye düşmüştür..$^{[1,2]}$ Ayrıca ameliyat sonrası hastanın erken mobilize olabilmesi ve yoğun rehabilitasyon gerektirmemesi de diğer avantajlar arasında sayılabilir.

Amerika Birleşik Devletleri'nde 1990-2002 yılları arasında uygulanan TKP sayısında $\% 50$, total diz protezi (TDP) sayısında ise üç kat artış olduğu bildirilmiştir. ${ }^{[2]}$ ileride revizyon sayılarının da buna paralel olarak

- İletişim adresi: Yrd. Doç. Dr. İbrahim Azboy, Dicle Üniversitesi Tıp Fakültesi Ortopedi ve Travmatoloji Anabilim Dalı, Diyarbakır Tel: 0505 - 6452433 e-posta: ibrahimazboy@hotmail.com

- Geliș tarihi: 26 Mart 2013 Kabul tarihi: 3 Haziran 2013 
ciddi oranda artacağı öngörülmektedir. Bu nedenle primer artroplasti uygulamasına bazı sınırlama mekanizmalarının getirilmesi gerektiği öne sürülmüştür. ${ }^{[2]}$ Ülkemizde kayıt sitemleri henüz yeterli olmadığından, elimizde net veriler olmasa da, uygulanan artroplasti sayısında artış olduğu gözlenmektedir. TKP uygulamasında; doğru endikasyon, titiz hazırlık, donanımlı hastane koşulları, eğitimli personel ve uygun cerrahi teknikle çok başarılı sonuçlar alınabileceği gibi, bu aşamalardaki eksiklikler veya hatalar, hem hasta, hem hekim ve hem de ülke ekonomisi için ağır bedellere neden olabilmektedir. Bu çalışmada, primer TKP'de hasta seçimi, endikasyonlar ve kontrendikasyonlar irdelenecektir.

ilk uygulamalarda, TKP için primer endikasyonun 65 yaşını geçmiş ve konservatif yöntemlerden fayda görmemiş olan hastalarda, ağrının hafifletilmesi olduğu kabul edilirdi. Ancak, ankilozan spondilit (AS) ve romatoid artrit (RA) gibi inflamatuar hastalıklarda her yaşta TKP uygulanabilmektedir. AS ve RA'li hastalarda diz ve ayak bileklerinde hareket kısıtlılığı gelişmeden hastaların total kalça protezi ile hareketlendirilmesi daha fazla önem taşır. ${ }^{[1]}$

TKP'de elde edilen yüksek başarı daha genç yaştaki hastalarda da benzer başarının elde edilip edilemeyeceğinin sorgulanmasına neden olmuştur. ${ }^{[3]}$ İmplant teknolojisindeki hızlı gelişmelerle birlikte daha dayanıklı protezler üretilmeye başlanmıştır. ${ }^{[4]}$ Öte yandan, hastalar uzun yıllar ağrı ve hareket kısıtlılığı ile yaşamak yerine ağrısız ve hareketli kalçaları ile işlerine, sosyal ve sportif aktivitelerine devam etmek istemektedirler. ${ }^{[5]}$ Bu nedenlerden dolayı daha erken yaşlarda, hastalara TKP ameliyatı önerilmeye ve uygulanmaya başlanmıştır. $^{[3,6]}$ Her ne kadar daha uzun süre sağkalımı öngörülen implantlar üretilse de, genç hastalar aktif yaşamlarına devam edeceklerinden, bu hastaların protezlerinin sonuçta gevşeyeceği ve revizyon ihtiyacının doğacağı açıktır. ${ }^{[7]}$ Revizyon ameliyatları, primer ameliyatlara göre daha zor ve sorunludur. Kemik stokunun kaybı, enfeksiyon ve çıkık riskinin artması en sık karşılaşılan sorunlar arasındadır. Ayrıca yaşın ilerlemesi ve eşlik eden sistemik hastalıklar, revizyon ameliyatlarını daha zor hale getirmektedir. ${ }^{[7,8]}$ Bu nedenle TKP'de hasta seçimi ve cerrahinin zamanlaması, en az uygulama tekniği kadar önemlidir. ${ }^{[9]}$

TKP uygulaması yaşı genç nüfus için aşağıya indiği gibi, yaşlılarda da uygulama yaşı normalde kabul edilen 60-75 yaş aralığının biraz üstüne çıkmıştır. ${ }^{[1]}$ Nüfusun yaşlanması ile, pek çok yaşlı hasta artroplasti adayı haline gelmektedir. ${ }^{[1]}$ Brander ve ark. ${ }^{[10]}$ TKP uygulanan 80 yaşın üzerindeki 99 hastada yaptıkları çalışmada, kontrol grubu ile kıyasladığında, komplikasyon oranları veya hastanede kalma süreleri açısından daha genç nüfusa oranla belirgin bir fark olmadığını ve fonksiyonel kazançların benzer olduğunu göstermişlerdir. Aynı şekilde, Berend ve ark. ${ }^{[11]}$ TKP uyguladıkları 89 yaş ve üzerindeki 56 hastanın ortalama 2,5 yıllık takiplerinde, kalça skorlarında belirgin düzelme görüldüğünü; hastaların sağkalımlarının, yaşları eşleştirilmiş popülasyona göre en azından benzer ve perioperatif medikal komplikasyonların, ölüm (\%14) hariç benzer olduğunu; bu nedenle hasta seçimi ve tedavinin dikkatli yapılması kaydıyla, 89 yaşından büyük hastalarda bile total kalça artroplastisinin başarı ile uygulanabileceğini belirtmişlerdir.

Dejeneratif kalça sorunlarında, artroplasti dışı tedavi seçenekleri öncelikle göz önünde tutulmalıdır. $\mathrm{Bu}$ tedavi seçeneklerinin avantajları ve dezavantajları, hastaya ayrıntılı bir şekilde sunulmalıdır. Genç ve aktif hastalarda, özellikle erkeklerde, kalçanın tek taraflı etkilendiği avasküler nekroz veya postravmatik artritte, artrodez halen bir seçenektir. Uygun pozisyonda artodez sağlandığında, kişi aktivitelerine dönebilmekte ve gerekirse daha ileri bir yaşta, artrodez total kalça artroplastisine başarılı bir şekilde çevrilebilmektedir. ${ }^{[12,13]}$

Hipertrofik artriti olan hastalarda, yeterli eklem hareketi varsa ve eklem belirgin şekilde uyumsuz hale gelmediyse, femoral veya periasetabuler osteotomi seçenekleri değerlendirilmelidir. ${ }^{[14]}$ Femur başındaki etkilenen alanın küçük olduğu idiyopatik osteonekrozda, kor dekompresyon ile beraber vaskülarize fibula grefti ve osteotomi ameliyatları düşünülmelidir. ${ }^{[15,16]}$ Her ne kadar erken dönemde artoplastide elde edilen hareket açıklığındaki artma ve ağrıda azalma, osteotomiye oranla daha iyi olsa da, uzun dönemde artroplastinin majör komplikasyonları olan belirgin kemik kaybı, gevşeme ve enfeksiyon gibi riskler göz önünde bulundurulmalıdır. Displazisi olan hastalarda yapılan periasetabuler osteotomi, artroplastiye geçildiğinde ortaya çıkacak yapısal kemik grefti ihtiyacını azaltır. Artroplasti yapıldığında hasta daha yaşı ı ve daha az aktif olacağından, kalça protezini daha kısa süre kullanması gerekecektir. Böylece hasta, revizyon ihtiyacı olmadan uzun süre protezini kullanabilecektir. ${ }^{[1,14]}$

TKP geri dönüşü olmayan majör bir cerrahidir. TKP seçeneği söz konusu olduğunda, cerrah öncelikle hastanın ameliyattan beklentilerinin neler olduğunu anlamaya çalışmalıdır. Bunun için hastaya vakit ayrılmalı ve detaylı olarak hastanın beklentileri sorgulanmalıdır. Hastanın beklentilerinin gerçekçi olup olmadığına karar vermek cerrahın görevidir. Örneğin, ağrısı çok az olduğu halde, ekstremite kısalığından dolayı topallamadan yürümek isteyen genç bir hastayı ameliyattan vazgeçirmeye çalışmak gerekir. Bunun için ameliyatın komplikasyonlarını ayrıntılı bir şekilde anlatmak, hatta 
ölüm riskinden bahsetmek, hastayı ameliyattan vazgeçirmeye çoğu zaman yetecektir. Öte yandan, şiddetli ağrısı olan ve vücut fonksiyonları ileri derece kısıtlandığı halde, ameliyatın komplikasyonları hakkında gerçekçi olmayan bilgileri nedeniyle ameliyattan korkan hastaları ise ameliyat olmaları için cesaretlendirmek gerekir.

Hasta, az veya çok bazı beklentilerini gerçekleştirmek için ameliyat olmak ister. Dolayısıyla hasta, ameliyattan umduğu sonucu bulamadığında, başka bir ifade ile evdeki hesap çarşıdakine uymadığında, hayal kırıklığına uğrar. Sonuçta, hekimi başarısızlıkla veya yeterli bilgi vermemekle suçlamaya başlar. Bu nedenle hastanın ve cerrahın ameliyattan beklentilerinin paralel olması gerekir. Nitekim, hastaların ve ameliyatı yapan cerrahların total kalça ve diz artroplastisinden beklentilerini karşılaştıran bir çalışmada, ${ }^{[17]}$ hastaların \%50'sinin kendilerini ameliyat eden cerrahlara göre ameliyattan daha fazla beklentileri olduğu gösterilmiştir. Özellikle hastaların yüksek aktivite ve aşırı kalça hareketi beklentilerinin karşılanmadığı görülmüştür. TKP'den beklentileri analiz eden başka bir çalışmada, Mancuso ve ark. ${ }^{[18]}$ TKP uygulanan 1103 hastadan, ameliyat öncesi fonksiyonları kötü olan erkek ve yaşlı hastaların ameliyattan beklentilerinin yüksek olduğunu belirtmişler ve gerçekçi olmayan beklentilerin ameliyat öncesinde hasta ile tartışılması gerektiğini öne sürmüşlerdir. Ameliyat öncesinde oluşturulan sınıflarda verilen eğitim sayesinde, TKP ve TDP uygulanan hastaların beklentilerinin azaldığı ve cerrahların önerilerine paralel hale geldiği bildirmiştir. ${ }^{[19]}$

TKP ameliyatından önce hastanın genel durumu detaylı olarak değerlendirilmelidir. Hastanın ameliyat sırasında kaybedeceği kan miktarını tolere edip edemeyeceği önemlidir. Bu nedenle, anemisi varsa düzeltilmelidir. Hastanın ameliyat öncesi tespit edilen hastalıkları tedavi edilmeli, kronik hastalıkları kontrol altına alınmalıdır. Özellikle diyabetinin düzenlenmesi önemlidir. Tüm vücut ve özellikle ameliyat edilecek kalça iyi değerlendirilmelidir. Abduktor kas gücü, her iki ekstremite arasında uzunluk farkı olup olmadığı, kalça fleksiyon, abduksiyon veya adduksiyon kontraktürleri ve alt ektremitenin rotasyonel deformiteleri belirlenmelidir. Karşı kalçada ya da dizde füzyon veya fleksiyon kontraktürü varlığının, TKP uygulanacak olan kalçaya ek yük getireceği unutulmamalıdır. ${ }^{[1]}$ Total kalça protezi uygulamasında dikkat edilmesi gereken kriterler Tablo 1'de verilmiştir. ${ }^{[20]}$

Swanson ve ark. ${ }^{[21]}$ aynı seansta her iki kalçaya ve tek kalçaya TKP uygulanan 400'er hastayı geriye dönük olarak karşılaştırdıkları çalışmada, ameliyat öncesi ASA (American Society of Anesthesiologists) skoru 1 ve 2 olan olgularda, aynı seansta her iki kalçanın kabul edilebilir perioperatif riskle ameliyat edilebileceğini öne sürmüşlerdir. Aynı seansta her iki kalçaya TKP uygulamasının temel endikasyonu, hastanın her iki kalçasında ileri derecede sertlik veya fleksiyon kontraktürü olmasıdır. Çünkü bu hastalarda tek taraflı girişimden sonra yeterli rehabilitasyon yapmak oldukça zordur. Bu uygulama, diyabet ve kardiyopulmoner hastalıkları olan yaşlı hastalar için uygun değildir. Tanısı kesinleştirilmiş patent duktus arteriosus, veya septal defekt varlığı ise kesin kontrendikasyon olarak kabul edilmektedir. İki taraflı uygulamada, anestezi ekibinin hastayı çok sıkı takip etmesi gereklidir. Diğer kalçanın ameliyatına, hastanın genel durumu izin verirse başlanmalıdır. ${ }^{[1]}$ Aynı seansta iki taraflı TKP uygulamasının yalnızca donanımlı kliniklerde ve çok deneyimli cerrahlar tarafından uygulanması gerektiğini belirtmek gerekir.

\section{TOTAL KALÇA ARTROPLASTISi ENDIKASYONLARI}

Kalçayı ilgilendiren hastalıklarda total kalça artroplastisi, geri dönüşü olmayan radikal bir karardır. TKP genel olarak iki durumda önerilmektedir. Bunlardan ilki, sıklıkla ağıı ve fonksiyon kısıtılığı ile seyreden kalça ekleminin kronik hastalıklarıdır. Dejeneratif ve inflamatuar kökenli kalça eklemi hastalıkları bu grupta değerlendirilebilir. Hızlı veya yavaş seyirli olabilirler. Bacak boyu eşitsizliği görülebilir. Aksama, pelvik dengesizlik ve buna bağlı omurga sorunları görülebilir. ikincisi, kemik defektlerine neden olan durumlardır. Bu grupta, kalça kırıkları, psödoartrozlar ve kalça çevresi tümörler sayılabilir. Total kalça artroplastisi endikasyonları Tablo 2'de özetlenmiştir. ${ }^{[22]}$

Total kalça artroplastisi uygulamasında cerrahiye karar verdiren en önemli bulgu ağrıdır. Hastaya, kalçanın majör ameliyatı olan TKP önerilmeden önce; kilo verme, analjezik tedavi, mantıklı ölçüde aktiviteleri azaltma, fiziksel olarak aktif bir işten daha az aktivite gerektiren bir işe girme ve baston kullanma gibi tüm konservatif yöntemler denenmelidir. Bu yöntemler, genellikle hastanın şikayetlerini azaltır. Sonuçta ya cerrahi tedavi gereksiz kalır ya da cerrahi gereksinim uzun bir süre ertelenmiş olur. ${ }^{[1]}$

Tüm konservatif tedavi yöntemlerine rağmen, hastanın günlük işlerinde ağrısı oluyorsa, yürüme mesafesi belirgin olarak kısalmışsa, aktivite değişikliklerine ve analjeziklere rağmen ağrısı devam ediyorsa ve özellikle gece ağrısı varsa, total kalça artroplastisi endikasyonu gündeme gelir. ${ }^{[1]}$ Ağrısı hiç olmayan veya çok az olan, ama hareket kısıtlılığı, ekstremitelerde uzunluk farkı ve topallama gibi şikayetlerle başvuran hastalara TKP uygulanmamalıdır. 
Tablo 1. Total kalça artroplastisi uygulaması kararı verilirken dikkat edilmesi gereken kriterler $^{\mathrm{a}}$

\begin{tabular}{lc}
\hline 1. Semptomlar ve bulgular & 2. Diğer parametreler \\
\hline Ağrı & Yaş ve yaşam beklentisi \\
Şiddeti & 50 yaş altı \\
İstirahat ağrısı & 80 yaşüstü \\
Yansıyan ağıı & Eşlik eden hastalıklar \\
Fonksiyon kaybı & Aşırı alkol kullanımı \\
Yürüme mesafesi & Şişmanlık \\
Destek kullanma ihtiyacı & Fiziksel faktörler \\
Merdiven çıkmada zorluk & Derin ven trombozu öyküsü \\
Ayakkabı ve çorap giymede güçlük & Arteryel ve venöz yetmezlik \\
Hareket açıklığında kısıtlanma & Kalça çevresi kaslarını ilgilendiren nörolojik hastalık \\
Kalçada instabilite & ileri kemik kaybı \\
Kalça abdüktör kas gücü & Yumuşak doku örtüsünün yetersiz olması \\
Fizik muayene bulguları & Kronik depresyon \\
Eklem aralığında daralma & Demans \\
& Kişilik bozukluğu \\
& Kooperasyon güçlüğü \\
& Fonksiyonel beklentiler \\
& Işse dönme isteği \\
& Spora dönme isteği \\
& Gerçek dışı beklentilerin varlığı \\
\hline
\end{tabular}

a 20 numaralı kaynaktan değiştirilerek alınmıştır.

Tablo 2. Total kalça artroplastisi endikasyonları ${ }^{\mathrm{a}}$

1. Artritler

2. Avasküler nekroz

3. Piyojenik artrit ya da osteomyelit

4. Tüberküloz

5. Konjenital subluksasyon ya da dislokasyon

6. Başarısız rekonstrüksiyon

7. Proksimal femur ya da asetabulumu içeren kemik tümörleri

8. Herediter bozukluklar (Akondroplazi gibi)

a 22 numaralı kaynaktan değiștirilerek alınmıştır.
Romatoid artrit

Juvenil Romatoid Artrit (Still hastalığı)

Ankilozan spondilit

Osteoartrit

Primer

Sekonder

Femur başı epifiz kayması

GKD

Perthes hastalığı

Travmatik kalça çıkığı

Asetabulum kırı̆ğ

Kırık ya da çıkı̆̆a bağlı

İiopatik

Femur bașı epifiz kayması

Hemoglobinopatiler (Orak hücreli anemi gibi)

Böbrek hastalıkları

Kortizon kullanımı

Alkolizm

Caisson hastalığı

Lupus

Başı da içeren femur boyun ya da trokanterik bölge kırıkları

Hematojen

Postoperatif

Osteotomi

Parsiyel kalça protezleri

Total kalça artroplastisi

Yüzey değiştirme (Resurfacing) artroplastisi 
Tablo 3. Total kalça artroplastisi kontraendikasyonları ${ }^{a}$

\begin{tabular}{l} 
Kesin kontraendikasyonlar \\
\hline Aktif enfeksiyon varlığı \\
Kalçada aktif enfeksiyon \\
Vücudun başka bir yerinde aktif enfeksiyon
\end{tabular}

Mortaliteyi ve morbiditeyi çok arttıracak instabil medikal hastalık

Göreceli kontraendikasyonlar
Kalça çevresinde geçirilmiş enfeksiyon
Aşırı şişmanlık
Sosyal olarak aşırı aktif hasta
Genç yaş
Charcot eklemi
Nörolojik hastalar
Abdüktör kasların kaybı
Demans veya akıl hastalığı
Ekstremitede ileri arteryel veya venöz yetmezlik
Başarılı kalça artrodezi
Yumuşak doku örtüsünde yetersizlik
Ameliyattan sağlık dışında ikincil beklenti olması
Cerrahın deneyiminin yetersiz olması
Sağlık kuruluşunun koşullarının yetersiz olması

a 22 numaralı kaynaktan değiştirilerek alınmıştır.

\section{TOTAL KALÇA ARTROPLASTISi KONTRENDIKASYONLARI}

TKP'nin başarısında hasta seçimi kadar, hangi hastalara TKP uygulanmaması gerektiği de önemlidir. TKP, beraberinde önemli komplikasyonların gelişebildiği ve mortalite oranının \%1-2 arasında olduğu majör bir cerrahi girişimdir. ${ }^{[7,23]}$ Bu nedenle TKP endikasyonu konduğu zaman hastanın çok dikkatlice değerlendirilmesi ve majör cerrahiye izin vermeyecek sistemik hastalıkların varlığı açısından iyice araştırılması gerekir. Dolayısıyla ameliyat öncesi dönemde hastanın gerekli konsültasyonları yapılmalıdır. Bazı hastalarda, majör cerrahi girişimden önce, düzeltilmesi gereken kardiyopulmoner, metabolik, genitoüriner, karaciğer sorunları ile hipertansiyon ve gizli maligensilerin mevcut olabileceği unutulmamalıdır.

TKP için kesin kontrendikasyonlar; kalçada veya kalça dışı diğer bölgelerde aktif enfeksiyon varlığı ve hastanın morbidite ya da mortalitesini önemli ölçüde arttıracak olan sistemik hastalıkların varlığıdır. ${ }^{[1]}$ Charcot eklemi, abduktor kasların kaybı, hızlı ilerleyici nörolojik hastalıklar, demans ve başarılı kalça artrodezi ise göreceli kontrendikasyon olarak belirtilmektedir. ${ }^{[1]}$ Total kalça protezinin kontrendikasyonları Tablo 3'te detaylı olarak verilmiştir. ${ }^{[22]}$

Sonuç olarak, TKP geri dönüşü olmayan majör bir cerrahidir. Bu nedenle tüm konservatif yöntemler denendikten sonra, hastaya en son seçenek olarak önerilmelidir. TKP'de endikasyon ve hasta seçiminde titiz davranmak başarıyı arttıracaktır.

\section{KAYNAKLAR}

1. Harkess JW, Crockarell Jr JR. Arthroplasty of hip. In: Canale ST, Beaty JH, eds. Campbell's Operative Orthopaedics. 11th ed. Philadelphia: Mosby Elsevier; 2012. chap 3.

2. Kurtz S, Mowat F, Ong K, Chan N, Lau E, Halpren M. Prevelance of primary and revision total hip and knee arthroplasty in the United States from 1990 through 2002. J Bone Joint Surg Am 2005;87(7):1487-97.

3. Polkowski GG, Callaghan JJ, Mont MA, Clohisy JC. Total hip arthroplasty in the very young patient. J Am Acad Orthop Surg. 2012;20(8):487-97. CrossRef

4. Muratoglu OK, Bragdon CR, O'Connor DO, Jasty M, Harris $\mathrm{WH}$. A novel method of cross-linking ultra-high-molecularweight polyethylene to improve wear, reduce oxidation, and retain mechanical properties. Recipient of the 1999 HAP Paul Award. J Arthroplasty 2001;16(2):149-60.

5. Wright JG, Rudicel S, Feinstein AR. Ask patients what they want: evaluation of individual complaints before total hip replacement. J Bone Joint Surg Br 1994;76(2):229-34.

6. Hernigou P, Zilber S, Filippini F, Poignard A. Ceramic-ceramic bearing decreases osteolysis: a 20-year study versus ceramicpolyethylene on the contralateral hip. Clin Orthop Relat Res 2009;467(9):2274-80. CrossRef

7. Thompson R, Kane RL, Gromala T, McLaughlin B, Flood S, Morris N, Borbas C. Complications and short-term outcomes associated with total hip arthroplasty in teaching and community hospitals. J Arthroplasty 2002;17(1):32-40.

8. Berry DJ, Harmsen WS, IIstrup DM. The natural history of debonding of the femoral component from the cement and its effect on long-term survival of Charnley total hip replacements. J Bone Joint Surg Am 1998;80(5):715-21.

9. Mancuso CA, Sculco TP, Salvati EA. Patients with poor preoperative functional status have high expectations of total hip arthroplasty. J Arthroplasty 2003;18(7):872-8.

10. Brander VA, Malhotra S, Jet J, Heinemann AV, Stulberg SD. Outcome of hip and knee arthroplasty in persons aged 80 years and older. Clin Orthop Relat Res 1997;(345):67-78. 
11. Berend ME, Thong AE, Faris GW, Newbern G, Pierson JL, Ritter MA. Total joint arthroplasty in the extremely elderly: hip and knee arthroplasty after entering the 89th year of life. J Arthroplasty 2003;18(7):817-21.

12. Murrell GA, Fitch RD. Hip fusion in young adults. Using a medial displacement osteotomy and cobra plate. Clin Orthop Relat Res 1994;(300):147-54.

13. Fernandez-Fairen M, Murcia-Mazón A, Torres A, Querales V, Murcia A Jr. Is total hip arthroplasty after hip arthrodesis as good as primary arthroplasty? Clin Orthop Relat Res 2011;469(7):1971-83. CrossRef

14. Steppacher SD, Tannast M, Ganz R, Siebenrock KA. Mean 20-year followup of Bernese periacetabular osteotomy. Clin Orthop Relat Res 2008;466(7):1633-44. CrossRef

15. Lausten GS, Mathiesen B. Core decompression for femoral head necrosis. Prospective study of 28 patients. Acta Orthop Scand 1990;61(6):507-11.

16. Aldridge JM 3rd, Berend KR, Gunneson EE, Urbaniak JR. Free vascularized fibular grafting for the treatment of postcollapse osteonecrosis of the femoral head. Surgical technique. J Bone Joint Surg Am 2004;86-A Suppl 1:87-101.

17. Ghomrawi HM, Franco Ferrando N, Mandl LA, Do H, Noor $\mathrm{N}$, Gonzalez Della Valle A. How often are patient and surgeon recovery expectations for total joint arthroplasty aligned? Results of a pilot study. HSS J 2011;7(3):229-34.
18. Mancuso CA, Sculco TP, Salvati EA. Patients with poor preoperative functional status have high expectations of total hip arthroplasty. J Arthroplasty 2003;18(7):872-8.

19. Mancuso CA, Graziano S, Briskie LM, Peterson MG, Pellicci PM, Salvati EA, Sculco TP. Randomized trials to modify patients' preoperative expectations of hip and knee arthroplasties. Clin Orthop Relat Res 2008;466(2):424-31. CrossRef

20. Mancuso CA, Ranawat CS, Esdaile JM, Johanson NA, Charlson ME. Indications for total hip and total knee arthroplasties. Results of orthopaedic surveys. J Arthroplasty 1996;11(1):34-46.

21. Swanson KC, Valle AG, Salvati EA, Sculco TP, Bottner F. Perioperative morbidity after single-stage bilateral total hip arthroplasty: a matched control study. Clin Orthop Relat Res 2006;451:140-5.

22. Temelli Y, Kılıçoğlu Ö. Total kalça protezinde hasta seçimi ve zamanlama. In: Yazıcıoğlu Ö, Salvati EA, Göksan SB, Kılıçoğlu Ö, editors. Total Kalça Artroplastisi. 1st ed. İstanbul: Ekin Yayıncılık; 2009. s. 116-22.

23. Poultsides LA, Ma Y, Della Valle AG, Chiu YL, Sculco TP, Memtsoudis SG. In-Hospital Surgical Site Infections after Primary Hip and Knee Arthroplasty - Incidence and Risk Factors. J Arthroplasty 2013;28(3):385-9. CrossRef 